\title{
Immortal Activated Human Hepatic Stellate Cells Generated by Ectopic Telomerase Expression
}

\author{
Bernd Schnabl, Youkyung Hwang Choi, John C. Olsen, Curt H. Hagedorn, and \\ David A. Brenner
}

\begin{abstract}
Departments of Medicine (BS, JCO, DAB) and Biochemistry and Biophysics (BS, DAB), University of North Carolina at Chapel Hill, Chapel Hill, North Carolina; and Department of Medicine (YHC, CHH), Emory University School of
\end{abstract} Medicine, Atlanta, Georgia

\begin{abstract}
SUMMARY: Telomere shortening controls the entry of cells into senescence. Functional expression of the telomerase catalytic subunit (human telomerase reverse transcriptase or hTERT) stabilizes telomere length and extends the life span of various normal human cells. Our aim was to assess the role of telomerase activity and telomere maintenance in regulating the proliferation of activated human hepatic stellate cells (HSCs), to establish an immortal human HSC cell line. Human HSCs were isolated from surgical specimens of normal liver and infected with a retrovirus expressing hTERT. Ectopic expression of hTERT reconstituted telomerase activity and maintained telomere length in human HSCs. Control human HSCs, which were either not infected or infected with a retroviral vector containing only the neomycin resistance gene, showed no detectable telomerase activity and had slightly shortened telomeres. These telomerase-negative HSCs entered a nondividing state after about 9 to 15 passages and senesced. In contrast, telomerase-positive HSCs to date have undergone 69 passages. Telomerase-positive HSCs did not undergo oncogenic transformation and exhibit morphologic and functional characteristics of activated HSCs. Microarray and RT-PCR analysis showed that mRNA expression patterns in telomerase-positive HSCs are very similar to those in activated human HSCs. Plating telomerase-positive HSCs on a basement membrane-like matrix reverts them toward a more quiescent phenotype. In conclusion, introduction of hTERT into activated human HSCs immortalizes them and maintains their activated phenotype. This newly developed cell line will be a useful tool to study the cell biology of human HSCs in culture. (Lab Invest 2002, 82:323-333).
\end{abstract}

\begin{abstract}
$T$ iver fibrosis is a common consequence of chronic L liver injury and is characterized by the progressive accumulation of extracellular matrix (ECM) proteins, particularly type I and III collagens (Friedman, 2000). Hepatic stellate cells (HSCs) are the major source of ECM in hepatic fibrosis (Maher et al, 1988; Maher and McGuire, 1990). In normal liver, HSCs are located in the subendothelial space and are the major storage site of vitamin A (Blomhoff and Wake, 1991). After hepatic injury, HSCs undergo an activation process, characterized by loss of vitamin A (Mak et al, 1984), transdifferentiation to a smooth muscle $\alpha$-actin $(\alpha \mathrm{SMA})$-positive myofibroblast-like cell type (de Leeuw et al, 1984; Ramadori et al, 1990), increased proliferation (Geerts et al, 1991) and increased production of ECM proteins, especially type I collagen (Takahara et al, 1988). Culturing HSCs on plastic converts them from a quiescent to an activated phenotype similar to in vivo activation.
\end{abstract}

Received November 27, 2001.

This study was supported in part by grants from Deutsche Forschungsgemeinschaft Schn 620/1-1 (BS) and NIH Grants GM41804 (DAB), DK34987 (DAB), and $A A 11605$ (DAB).

Address reprint requests to: Dr. David A. Brenner, Department of Medicine, Division of Digestive Diseases and Nutrition, CB\# 7038, Glaxo Research Bldg., Rm. 156, University of North Carolina at Chapel Hill, Chapel Hill, NC 27599.E-mail: dab@med.unc.edu
Normal human cells in culture divide a limited number of times and then enter a nondividing state termed replicative senescence. Telomeres undergo progressive shortening with successive cell divisions in normal cells, and cellular senescence is thought to be induced when telomeres shorten beyond a critical length (Allsopp et al, 1992; Counter et al, 1992). Human telomeres consist of a repetitive DNA sequence (TTAGGG) ${ }_{n}$ at chromosome ends (Moyzis et al, 1988). This telomeric DNA is synthesized and maintained by telomerase, a ribonucleoprotein complex (Greider and Blackburn, 1989; Morin, 1989). Normal human cells do not express telomerase activity (Kim et al, 1994) and have short telomeres (de Lange et al, 1990). Recent studies have shown that introduction and expression of human telomerase reverse transcriptase (hTERT) maintains telomere length and extends the life span of human fibroblasts (Bodnar et al, 1998; Vaziri and Benchimol, 1998) and human embryonic kidney cells (Counter et al, 1998). Mice lacking telomerase RNA (mTR) demonstrate the importance of telomerase activity for cell growth and survival. In late generation mice, telomerase deficiency leads to shortened telomeres and an impaired long-term viability of embryonic stem cells and cells from highly proliferative organs, such as testis, bone marrow, and spleen (Lee et al, 1998; Niida et al, 1998). Germ cells from telomerase-deficient mice have de- 
fective spermatogenesis, with reduced proliferation and increased apoptosis (Lee et al, 1998).

The isolation of human HSCs is a time-consuming process and is dependent on the availability of liver specimens. Therefore, the aim of this study was to investigate the role of telomerase activity and telomere maintenance in the proliferation of human HSCs, to establish an immortal human HSC cell line. We demonstrate that activated human HSCs with no detectable telomerase activity and with shorter or undetectable telomeres senesce in culture, which is followed by cell death. In contrast, ectopic expression of telomerase immortalizes activated HSCs in culture. Telomerase-positive HSCs do not undergo oncogenic transformation and show morphologic characteristics of activated HSCs. In addition, microarray and RTPCR analysis demonstrated that mRNA expression patterns in telomerase-positive HSCs and activated human HSCs are very similar.

\section{Results}

\section{Introduction of Human Telomerase Reverse Transcriptase Restores Telomerase Activity and Maintains Telomere Length in Human Hepatic Stellate Cells}

HSCs, which were isolated from surgical specimens of normal human liver, displayed retinoid droplets and retained the characteristic vitamin A fluorescence even after 7 days in culture, although the amount of intracellular droplets varied among the cells at this time point (Fig. 1).

On day 9 after isolation, VSV-G pseudotyped retroviral vectors encoding hTERT, or a control retroviral vector expressing only the neomycin resistance gene, were introduced in HSCs. Polyclonal HSC populations and cloned cell line 14 were obtained by selection in $400 \mu \mathrm{g} / \mathrm{ml}$ G418. Semiquantitative RT-PCR demonstrated that hTERT mRNA was expressed at high levels in hTERT-infected HSCs (Fig. 2A). Early passage vector control-infected HSCs showed only minimal hTERT mRNA expression. Hela cells and primary human dermal fibroblasts (HDF) served as positive and negative controls, respectively. To determine whether ectopic expression of hTERT produced telomerase activity, a telomeric repeat amplification protocol (TRAP) assay was performed. Telomerase activity was detected in polyclonal HSCs and in clone
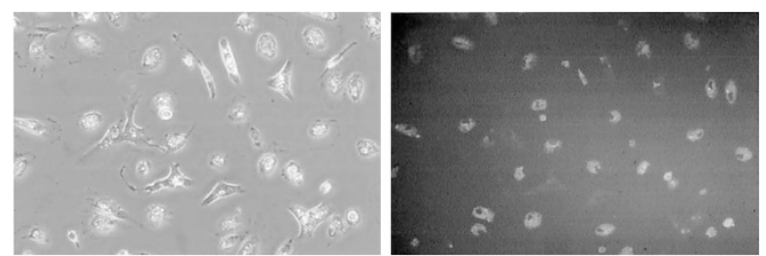

Figure 1.

Primary human hepatic stellate cells (HSCs) show the characteristic vitamin A fluorescence. Human HSCs were isolated and cultured for 7 days on uncoated plastic dishes. Cells are spread out and contain lipid droplets in the perinuclear zone under phase microscopy (left panel; original magnification, $\times 200$ ). Fluorescence microscopy demonstrates the fluorescence of vitamin A (right panel; original magnification, $\times 200$ ).
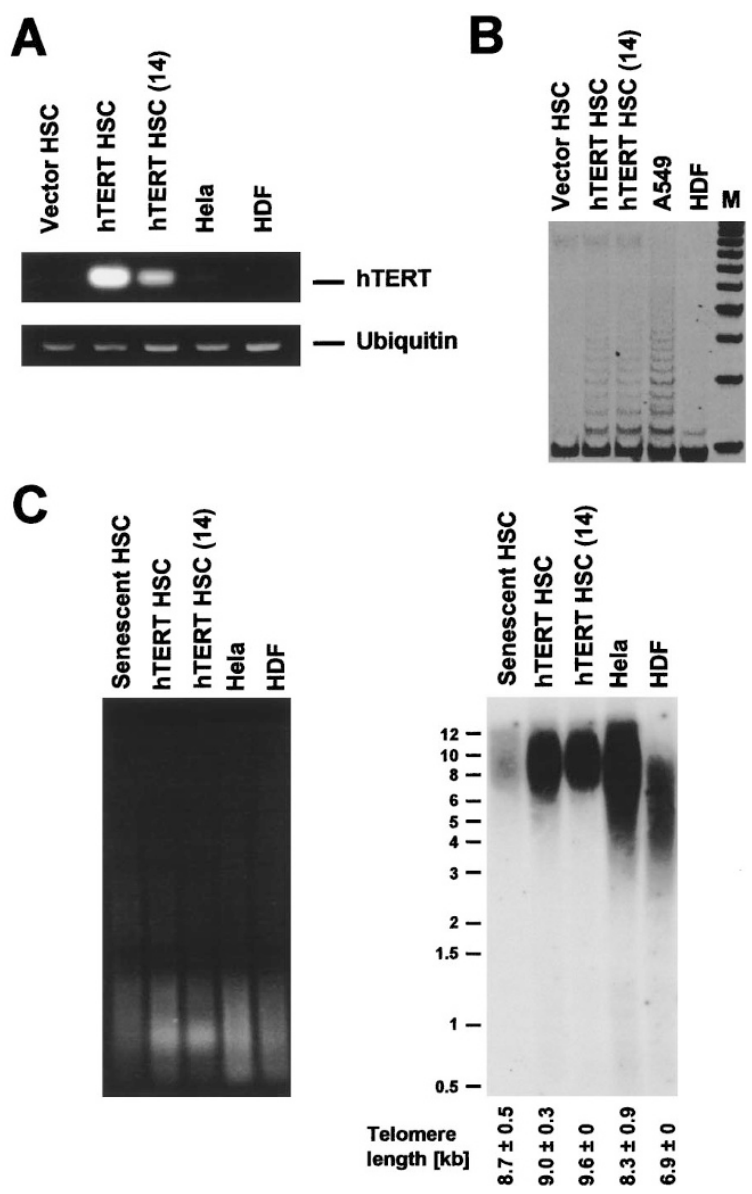

Figure 2.

Introduction of human telomerase reverse transcriptase (hTERT) in human HSCs leads to telomerase activity and permits maintenance of telomere length. Human HSCs were infected with a retrovirus encoding hTERT or a retroviral vector expressing only the neomycin resistance gene after 9 days in culture. Cells were selected in G418. A, The expression of hTERT was analyzed by semiquantitative RT-PCR using $1 \mu \mathrm{g}$ of total RNA. CDNA was analyzed from vector control-infected HSCs (vector) and from hTERT-infected HSCs (polyclonal and single-cell clone 14). Telomerase-positive Hela cells and telomerase-negative primary human dermal fibroblasts (HDF) served as positive and negative control, respectively. Ubiquitin (below) was amplified to confirm equal amount of mRNA was present in each sample. B, Telomerase activity was measured in HSCs infected with a control vector (vector) or a vector expressing hTERT (polyclonal HSCs and HSCs from clone 14) by the telomeric repeat amplification protocol (TRAP) assay. For each sample $10^{5}$ cells were lysed and analyzed for telomerase activity. Telomerase-positive A549 lung carcinoma cells were included as positive control, primary HDF as negative control. C, Left panel: Total genomic DNA $(2 \mu \mathrm{g})$ was digested, resolved by agarose gel electrophoresis, and visualized with ethidium bromide staining. Right panel: The telomere restriction fragment length was detected by Southern blot analysis with a ${ }^{32} \mathrm{P}$-labeled telomeric probe. HSCs infected with hTERT (polyclonal and clone 14) were compared with senescent HSCs. As a positive and negative control, telomerase-positive Hela cells and primary HDF, respectively, were used. The sizes $(\mathrm{Kb})$ of molecular mass marker are indicated. Shown is a representative experiment. The telomere restriction fragment length is indicated; data represent the mean \pm standard deviation (SD) of two experiments.

14 (telomerase-positive), which were retrovirally infected with the hTERT gene, and comparable to telomerase-positive A549 lung carcinoma cells (Fig. 2B). Early passage control-infected HSCs and HDF, which served as negative control, showed no telomerase activity (telomerase-negative). To demonstrate that telomerase activity maintained telomere length, 
the telomere restriction fragment length was measured by Southern blot analysis using a telomerespecific probe. Telomerase-positive polyclonal HSCs and clone 14 maintained a telomere restriction fragment length of $9.0 \pm 0.3 \mathrm{~Kb}$ and $9.6 \pm 0 \mathrm{~Kb}$, respectively, comparable to Hela cells as positive control (Fig. 2C). In telomerase-negative, late passage (senescent) HSCs, telomere restriction fragment length decreased to $8.7 \pm 0.5 \mathrm{~Kb}$ (Fig. 2C). This telomere shortening in telomerase-negative HSCs was accompanied by a decrease in the hybridization signal intensity. Comparable loading of the gel was demonstrated by ethidium bromide staining (Fig. 2C). Taken together, these results indicate that ectopic expression of hTERT reconstitutes telomerase activity and maintains telomere length in human HSCs.

Telomerase-Negative Hepatic Stellate Cells Senesce and Die, Telomerase-Positive Hepatic Stellate Cells Have an Extended Life Span

Uninfected and vector control-infected (telomerasenegative) HSCs senesced and entered a nondividing state after about 9 to 15 passages in culture. Similar findings were obtained from several other isolations of human HSCs, either uninfected or vector-control infected. Senescence of these cells was characterized by a flattened cell morphology, enlarged cell size, and an increased ratio of cytoplasm to nucleus (Fig. 3A). This nonproliferative state was followed by cell death. In contrast, telomerase-positive HSCs exceeded the life span of telomerase-negative HSCs, have undergone 69 passages to date, and continue to proliferate. Telomerase-positive HSCs exhibit the cell morphology of activated primary HSCs (Fig. 3A). Telomerasepositive HSC clone 14 showed a population doubling time of about 4 days in culture medium containing $10 \%$ FCS (Fig. 3B). After a period of serum starvation, stimulation of telomerase-positive HSC clone 14 with $10 \%$ FCS for 24 hours resulted in a 2.6 -fold increase of $\left[{ }^{3} \mathrm{H}\right]$ thymidine incorporation as compared with unstimulated HSCs (Fig. 3C). Thus, ectopic expression of functional hTERT in HSCs extends the life span and immortalizes human HSCs.

\section{Telomerase-Positive Hepatic Stellate Cells Do Not Show Signs of Oncogenic Transformation}

Although expression of telomerase in human fibroblasts is sufficient for immortalization, it does not result in changes associated with malignant transformation (Morales et al, 1999). Similarly in this study, telomerase-positive HSCs show a proliferation rate similar to that of primary (presenescent) HSCs, are contact inhibited at high cell density, and do not form foci of proliferating, multi-layered cells (data not shown). Serum growth factors for proliferation are required (Fig. 3C). The acquisition of anchorageindependent growth potential represents one of the best in vitro correlates to in vivo tumorigenic growth potential (Cox and Der, 1994). Therefore, we investigated whether ectopic telomerase expression induces anchorage-independent growth in HSCs. No colony
A
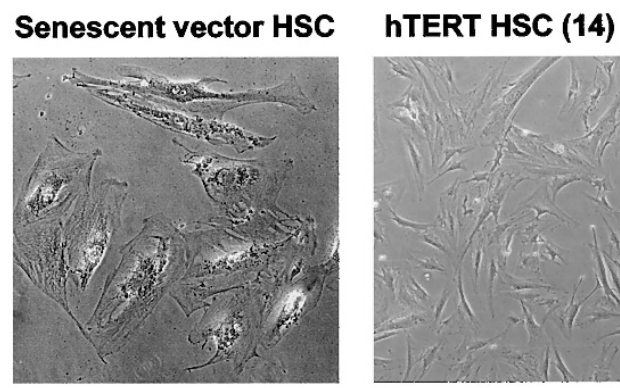

B
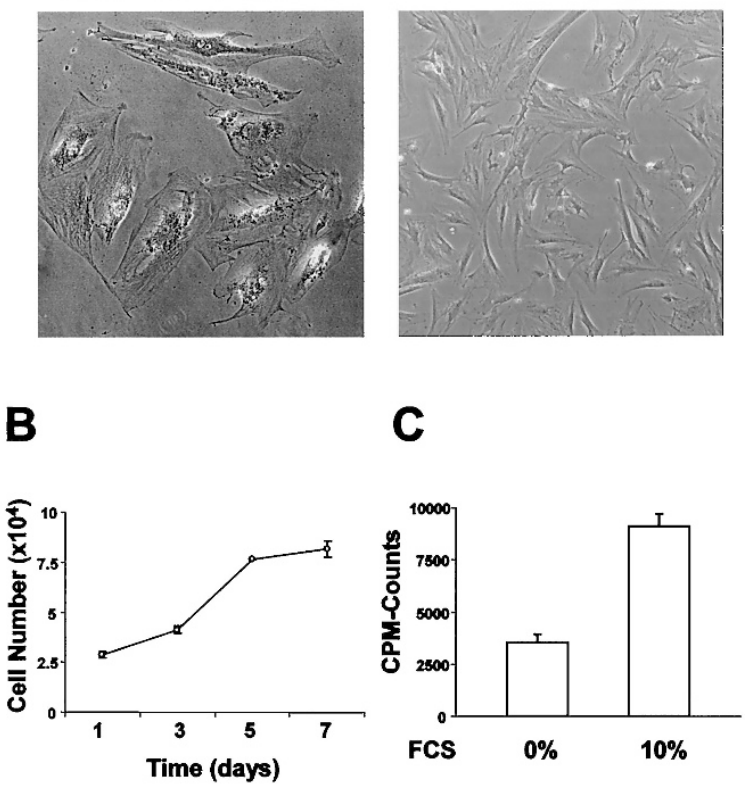

Figure 3.

Telomerase-negative HSCs senesce, whereas functional expression of telomerase extends the replicative life span of HSCs. A, Phase microscopy demonstrates the flattened cell morphology of senescent HSCs infected with a control vector (left panel; original magnification, $\times 100$ ) and the phenotype of telomerase-positive HSCs from clone 14 (right panel; original magnification, $\times 100$ ). B, To investigate the growth curve of telomerase-positive HSCs (clone 14), HSCs were plated in 35-mm dishes. Cell counts were performed in duplicate from day 1 to day 7 in culture using a hemacytometer. Data represent the mean $\pm \mathrm{SD}$. C, For $\left[{ }^{3} \mathrm{H}\right]$ thymidine incorporation assay, telomerase-positive HSCs (clone 14) were serum starved for 24 hours in serum-free medium and afterward stimulated with 10\% FCS for another 24 hours in medium containing $1 \mu \mathrm{Ci} / \mathrm{ml}\left[{ }^{3} \mathrm{H}\right]$ thymidine. HSCs maintained in $0 \%$ FCS served as a control. Experiments were performed in triplicate. Data represent the mean $\pm \mathrm{SD}$.

formation and no growth of telomerase-positive polyclonal HSCs (Fig. 4A) and HSCs from clone 14 (Fig. 4B) was observed after 6 weeks in soft agar. As a positive control, H-ras transformed NIH 3T3 cells did form colonies (Fig. 4C). As a negative control, NIH 3T3 cells transfected with the empty vector pZIP$\operatorname{NeoSV}(x) 1$ did not form colonies (Fig. 4D). Taken together, these findings offer no evidence for the oncogenic transformation of telomerase-positive HSCs, which might have accounted for their extended life span.

Gene Expression Patterns of Telomerase-Positive Hepatic Stellate Cells Are Very Similar to those of Activated Human Hepatic Stellate Cells

Since an immortalized human HSC cell line represents a useful tool to investigate HSC biology, we characterized this newly developed cell line. Differences in gene expression patterns between telomerasepositive HSCs (passage 55) and activated human HSCs (passage 3) were assessed using microarray analysis. This array allows a quantitative measurement of over 9000 genes and expressed sequence tags. 

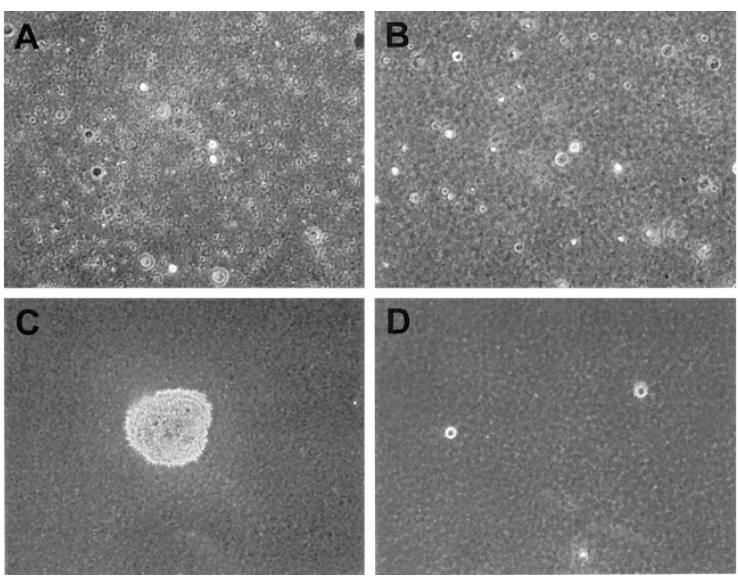

Figure 4.

Telomerase-positive HSCs lack anchorage-independent growth in soft agar. Telomerase-positive polyclonal HSCs (A) and HSCs from clone 14 (B) were plated in soft agar at a density of $10^{5}$ cells per $60-\mathrm{mm}$ dish. As positive control Ras-transformed (pZIP-H-ras(61L)) NIH 3T3 cells were used (shown is a small colony) (C). As a negative control, NIH 3 T3 cells transfected with the empty vector pZIP-NeoSV $(x) 1$ were used (D). Cells were captured at original magnification $\times 100$ after 6 weeks.

Genes that differed in intensity by at least 2-fold were considered to be differentially regulated. Scatter plot analysis shows that the vast majority of genes $(97.2 \%)$ was expressed at comparable levels (Fig. 5A). One hundred fifty-two genes (1.8\%) were detected at higher expression levels in activated human HSCs, whereas 87 genes $(1 \%)$ were detected at higher expression levels in telomerase-positive HSCs. A selection of genes with more than 2-fold difference in activated human HSCs and in hTERT HSCs is shown in Table 1. The complete list of all genes is available at our web site (http://www.med.unc.edu/wrkunits/2depts/ medicine/gi/brenlab/schnablarray1/). The microarray analysis was confirmed by RT-PCR of selective mRNAs. RT-PCR demonstrated that both telomerase-positive and activated HSCs express mRNA for IL-6, IL-8, IL-10, platelet-derived growth factor receptor alpha and beta, and glial fibrillary acidic protein (GFAP) (data not shown).

To further characterize telomerase-positive HSCs, the levels of collagen $\alpha 1(I)$ mRNA and $\alpha$ SMA protein, a phenotypic marker of activation for human HSCs (Schmitt-Graff et al, 1991), were investigated. Telomerase-positive polyclonal HSCs and clone 14 express collagen $\alpha 1(\mathrm{I}) \mathrm{mRNA}$ to a similar extent as (early passage) uninfected and vector control-infected HSCs (Fig. 5B), consistent with microarray analysis showing a 1.6-fold higher expression in telomerasepositive HSCs as compared with activated HSCs. Western blot analysis showed similar expression of $\alpha \mathrm{SMA}$ protein in telomerase-positive HSCs, uninfected, and vector control-infected HSCs (Fig. 5C).

\section{Telomerase-Positive Hepatic Stellate Cells Change Their Morphology and Collagen Type I mRNA Expression Upon Culture on a Basement Membrane-Like Matrix}

Freshly isolated rat or human HSCs maintain a quiescent phenotype when cultured in matrigel (Friedman et
A

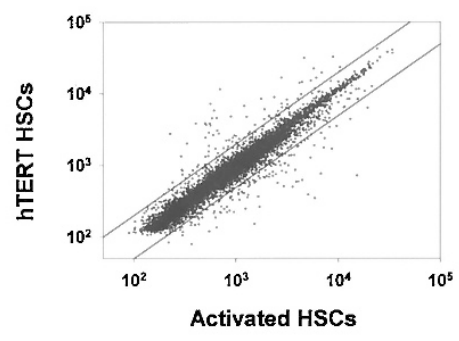

B

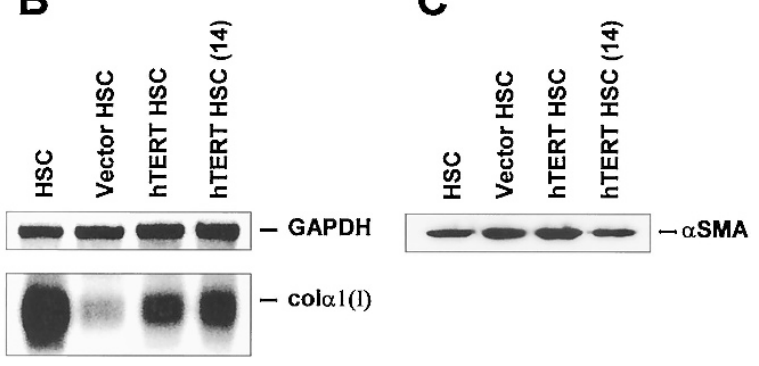

Figure 5.

Gene expression patterns in activated human HSCs and telomerase-positive HSCs. A, Microarray analysis of gene expression in activated human HSCs and telomerase-positive HSCs was performed. The values of all genes in activated human HSCs ( $x$ axis) and telomerase-positive HSCs ( $y$ axis) were compared using scatter plot analysis. The upper and lower diagonals represent 2-fold higher gene expression in telomerase-positive and activated human HSCs, respectively. B, Uninfected and vector control-infected HSCs, telomerasepositive polyclonal HSCs, and HSCs from clone 14 were cultured on plastic. Total RNA $(5 \mu \mathrm{g})$ was subjected to RNase protection assay with riboprobes specific for human collagen $\alpha 1(\mathrm{I})$ and human GAPDH mRNA. Migration of the protected bands is indicated. C, Western blot analysis was performed using whole cell extracts obtained from uninfected HSCs, vector control-infected HSCs, telomerase-positive polyclonal HSCs, and HSCs from clone 14. Proteins $(10 \mu \mathrm{g})$ were separated in a $12 \%$ SDS-PAGE, transferred to a nitrocellulose membrane, and immunoblotted for $\alpha \mathrm{SMA}$ using monoclonal anti-smooth muscle $\alpha$-actin antibody.

al, 1989, 1992), which is a solubilized basement membrane preparation from the Engelbreth-Holm-Swarm tumor. To evaluate whether telomerase-positive HSCs displaying an activated phenotype would revert to a more quiescent state by changing the culture substratum, telomerase-positive HSC clone 14 was plated in matrigel. HSCs lost their star-like shape, rounded up, and formed clusters, which were connected with filamentous bridges (Fig. 6A). After 15 days in matrigel, HSCs down-regulated their collagen $\alpha 1$ (I) mRNA expression by $48 \%$ as compared with HSCs grown under the same culture conditions on plastic, as assessed by RNase protection assay (Fig. 6B). HSCs cultured with DMEM or hormonally defined medium (HDM) on plastic showed similar levels of collagen $\alpha 1$ (I) mRNA (Fig. 6B). Thus, culturing telomerasepositive HSCs on a basement membrane gel induces reversion to a more quiescent appearance.

\section{Telomerase-Positive Hepatic Stellate Cells Take Up Exogenous Retinol}

HSCs store vitamin A in the quiescent state, which is lost upon activation (Mak et al, 1984). To assess 
Table 1. Comparison of Gene Expression in Activated Human HSCs and Telomerase-Positive HSCs using Microarray Analysis

\begin{tabular}{|c|c|}
\hline 21.1 & keratin 18 \\
\hline 13 & IL-1 receptor, type I \\
\hline 8.8 & mitochondrial superoxide dismutase 2 \\
\hline 6.4 & proteoglycan 1 \\
\hline 5 & fibroblast growth factor 7 \\
\hline 4.8 & cyclooxygenase 2 \\
\hline 4.6 & hepatocyte growth factor \\
\hline 4.4 & gp130 \\
\hline 4.2 & IL-6 \\
\hline 3.2 & laminin beta 1 \\
\hline 3.1 & Iow density lipoprotein receptor \\
\hline 3.1 & ICAM-1 \\
\hline 3 & IGFBP 5 \\
\hline 2.5 & IL-13 \\
\hline 2.4 & integrin alpha 1 \\
\hline 2.4 & PDGF receptor alpha \\
\hline 2.2 & p21 \\
\hline-2.4 & alpha-2-macroglobulin \\
\hline-2.4 & collagen, type IV, alpha 1 \\
\hline-2.6 & integrin alpha 3 \\
\hline-2.8 & connective tissue growth factor \\
\hline-2.9 & integrin alpha 7 \\
\hline-2.9 & tubulin alpha 1 \\
\hline-3.7 & plasminogen activator inhibitor type 1 (PAI 1) \\
\hline-3.8 & caveolin 2 \\
\hline-3.8 & $\alpha \mathrm{B}$ crystallin \\
\hline-4.7 & aggrecan 1 \\
\hline-4.8 & versican \\
\hline-6.4 & $\begin{array}{l}\text { latent transforming growth factor beta binding } \\
\text { protein } 1\end{array}$ \\
\hline-6.8 & fibronectin 1 \\
\hline-7.1 & IGFBP 1 \\
\hline-7.7 & IGFBP 3 \\
\hline-7.8 & caveolin 1 \\
\hline
\end{tabular}

HSCs, hepatic stellate cells; hTERT, human telomerase reverse transcriptase; ICAM, intercellular adhesion molecule; IGFBP, insulin-like growth factor binding protein; PDGF, platelet-derived growth factor.

A selection of genes with more than 2-fold difference in activated human HSCs and hTERT HSCs is shown. Genes that were present at higher levels in activated human HSCs have positive values, genes with higher expression levels in hTERT HSCs have negative values.

whether cultured telomerase-positive HSCs uptake retinol and store it as vitamin $\mathrm{A}$ in their cytoplasm, HSCs from clone 14 were incubated with $1.5 \mu \mathrm{M}$ retinol for 14 days. HSCs took up retinol and regained the characteristic autofluorescence of vitamin A storing quiescent HSCs (Fig. 7). HSCs treated with vehicle (ethanol) alone under the same conditions showed minimal autofluorescence (Fig. 7).

\section{Discussion}

This study demonstrates a role for telomerase activity and telomere length in regulating the proliferation of activated human HSCs in culture. The introduction of hTERT in human activated HSCs leads to expression of hTERT mRNA, reconstitutes telomerase activity, and maintains telomere length. Comparison of hTERT-
A

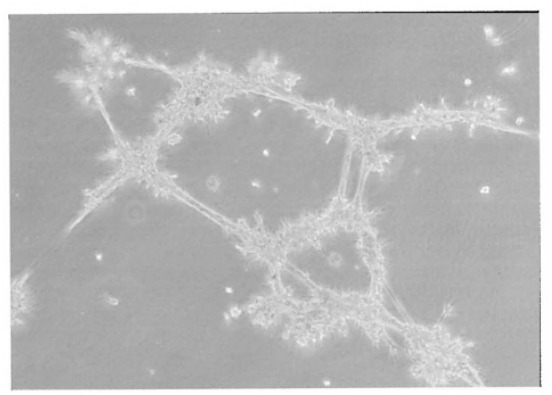

B
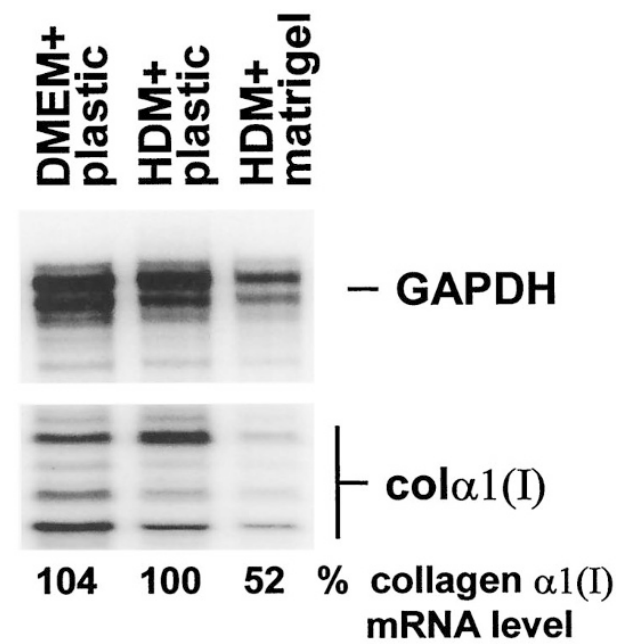

Figure 6.

Culturing telomerase-positive HSCs on a basement membrane-like matrix reverts them to a quiescent phenotype and down-regulates their collagen $\alpha 1$ (I) mRNA. Telomerase-positive HSCs from clone 14 were plated in matrigel, a basement membrane-like matrix, at a density of 4 to $6 \times 10^{5}$ per $60-\mathrm{mm}$ dish. A, Phase microscopy demonstrates cluster formation without visible spreading of telomerase-positive HSCs in matrigel (original magnification, $\times 100$ ). B, HSCs were maintained in matrigel in hormonally defined medium (HDM) containing $2 \%$ FCS for 15 days. As controls telomerase-positive HSCs from clone 14 were cultured on plastic for 15 days after plating, either in HDM containing $2 \%$ FCS or in regular growth medium containing $10 \%$ FCS. RNase protection assay with collagen $\alpha 1(\mathrm{I})$ and GAPDH gene-specific riboprobes and RNA $(3.5 \mu \mathrm{g})$ extracted from HSCs was performed. Migration of the protected bands is indicated. Expression of collagen $\alpha 1(\mathrm{I})$ mRNA was normalized to GAPDH mRNA, and the ratios are indicated. The results are expressed relative to HSCs cultured on plastic in HDM containing $2 \%$ FCS.

positive and hTERT-negative HSCs showed that stabilization of telomeres promotes cell survival and results in the immortalization of telomerase-positive human HSCs. We also demonstrate that ectopic expression of telomerase in HSCs is not associated with oncogenic transformation. The immortalized HSCs retain the morphologic characteristics of activated HSCs and show a gene expression pattern very similar to activated human HSCs.

Ectopic expression of hTERT reconstitutes telomerase activity, maintains telomere length, and extends the replicative life span of primary human retinal pigment epithelial cells and fibroblasts (Bodnar et al, 1998; Morales et al, 1999; Vaziri and Benchimol, 1998) and primary human endothelial cells (Yang et al, 1999). 


\section{Retinol}

\section{Ethanol}
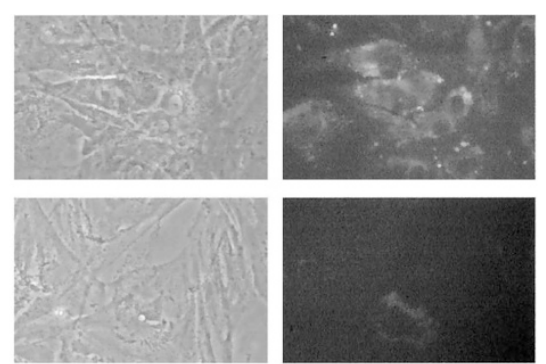

Figure 7.

Telomerase-positive HSCs take up retinol. Telomerase-positive HSCs from clone 14 were cultured in regular growth medium containing $1.5 \mu \mathrm{m}$ retinol. The fluorescence of vitamin A in the cytoplasm of HSCs was captured by fluorescence microscopy at a wavelength of $330 \mathrm{~nm}$ after an incubation time of 14 days. As control, HSCs were incubated with an equivalent amount of vehicle (ethanol); (left panels: phase microscopy; right panels: fluorescence microscopy; original magnification, $\times 200$ ).

The cell-cycle checkpoints, such as pRB, p53, and $\mathrm{p} 21^{\mathrm{CIP} 1 / \mathrm{WAF} 1}$, in these telomerase-expressing cells are similar to those of untransfected cells (Morales et al, 1999; Yang et al, 1999). For some cell types, such as primary human keratinocytes or mammary epithelial cells, introduction of hTERT is not sufficient to extend their life span, and other factors are necessary for immortalization (Hahn et al, 1999; Kiyono et al, 1998). However, as shown in our report, functional expression of hTERT in human HSCs with maintenance of telomere length is sufficient to extend their proliferative life span. Telomerase-positive HSCs continued to proliferate at a time when their counterparts, which were either not infected or infected with a control retroviral vector expressing only the drug resistance gene, senesced and died. To date, the telomerasepositive cells have been cultured for more than 2 years and have undergone 69 passages. Telomerasepositive HSCs did not show signs of a transformed phenotype, which might have enabled HSCs to overcome senescence and crisis, accounting for their extended life span. Therefore, we have not detected any additional extrinsic factors that are required to achieve immortalization in human HSCs.

We observed that HSCs infected with a control retroviral vector show detectable hTERT mRNA expression as assessed by RT-PCR, even though no telomerase activity was detectable. In general, expression of hTERT mRNA seems to be the limiting factor for telomerase activity in cells (Meyerson et al, 1997; Nakamura et al, 1997). However, in human lymphocytes, telomerase activity is not strictly correlated with the levels of hTERT transcripts, indicating that regulation of telomerase is cell type specific and that a posttranscriptional mechanism also plays a role in the control of telomerase function (Liu et al, 1999).

Telomere length in senescent human HSCs decreased slightly as compared with presenescent or telomerase-positive HSCs. In addition, the total hybridization signal decreased markedly in senescent human HSCs, which indicates that TTAGGG repeats are lost during the life span of human HSCs. Previous studies have shown a comparable decrease in telomere length and in the amount of telomeric DNA with cell age in vitro in different strains of primary human fibroblasts (Allsopp et al, 1992; Harley et al, 1990). Variability in telomere length has been described in different cell types (de Lange et al, 1990), and a heterogeneity of telomere length is associated with senescence in various human cells (4 to $7 \mathrm{~kb}$ ) (Counter et al, 1992, 1998). Thus, it seems that human HSCs are very sensitive in telomere shortening.

Beside this newly established telomerase-positive human HSC cell line, two other human HSC cell lines have been published; the LI90 cell line was derived from a human hepatic mesenchymal tumor (Murakami et al, 1995) and the GREF-X cell line was developed through spontaneous immortalization (Weill et al, 1997). However, the limitation of these two cell lines is that the cells are derived from connective tissue, and HSCs were obtained by outgrowth, rather than by purification on a density gradient. Neither cell line was compared with primary activated human HSCs. Thus, it remains unclear whether these human HSC cell lines actually have functional characteristics of activated HSCs.

In our study, microarray analysis revealed that gene expression patterns in telomerase-positive HSCs and activated HSCs are $97.2 \%$ similar. Despite a $2.8 \%$ difference in gene expression, we have not detected any phenotypical differences between hTERT HSCs and activated HSCs, including morphology and ECM production. One explanation for this lack of complete concordance is that gene expression patterns in activated HSCs might continually change upon passaging, and different mRNA expression patterns might even exist in HSCs with different passage numbers. One also has to consider that hTERT HSCs have ectopic hTERT mRNA expression and reconstituted telomerase activity. By maintaining telomere length in HSCs, gene regulation that is normally induced by shortened telomeres might be altered. For example, ectopic telomerase expression might eliminate DNA damage-induced signaling of the transcription factor p53 or ATM (ataxia telangiectasia mutated) kinase (Karlseder et al, 1999). Supportive of this idea is the fact that in early passage HSCs, a downstream effector of p53-induced cell arrest, p21 ${ }^{\mathrm{CIP} 1 / \mathrm{WAF} 1}$, is slightly up-regulated in activated HSCs as compared with hTERT HSCs. Since heterogeneity in the telomere size is prominent in all somatic cells (de Lange et al, 1990), telomere shortening in a subpopulation of HSCs might already be sufficient to change mRNA levels of the entire population. Similar to our results, another study using DNA microarray analysis found that gene expression patterns in early passage BJ fibroblasts are substantially similar but not identical with the gene expression patterns of their hTERT immortalized counterparts (Funk et al, 2000). Genes differentially expressed and up-regulated in telomerase immortalized fibroblasts included insulin-like growth factor binding protein-5, stromelysin-1, and stromelysin-2 (Funk et al, 2000). Thus, hTERT expression maintains very similar, but not identical, functional characteristics in HSCs, making this newly developed cell line a useful tool to study HSCs in culture. In addition, our 
microarray analysis on activated human HSCs should make research about gene expression in activated HSCs easier.

Although there are several cell types related to fibroblasts and myofibroblasts in the liver, HSCs are considered to be the principal source of ECM in hepatic fibrosis (Maher et al, 1988; Maher and McGuire, 1990). In an attempt to discriminate our telomerase-positive human HSC cell line from other mesenchymal cells and to demonstrate that telomerase-positive HSCs derive from activated HSCs, we analyzed the functional and phenotypic appearance of telomerase-positive HSCs. Telomerase-positive HSCs contained collagen $\alpha 1(\mathrm{I})$ mRNA to a similar extent as activated HSCs and secreted the protein into the medium (data not shown). Morphologically, telomerase-positive HSCs exhibit features of activated HSCs and express phenotypic markers for culture activated HSCs, such as $\alpha$ SMA protein, which is an activation marker for human HSCs (SchmittGraff et al, 1991), and mRNA for GFAP. The mRNA of GFAP, an intermediate filament and a neural marker of differentiation, is expressed by HSCs and is considered as a specific marker of HSCs (Neubauer et al, 1996). A recent in vitro study proposed that two different myofibroblastic cell populations isolated from rats, HSCs and liver myofibroblasts, are involved in liver tissue repair and fibrogenesis (Knittel et al, 1999). Rat HSCs were characterized by the expression of GFAP, vascular cell adhesion molecule-1, and $\alpha 2$-macroglobulin, whereas rat liver myofibroblasts were characterized by the mRNA expression for IL-6 and fibulin 2 (Knittel et al, 1999). Microarray analysis showed that telomerase-positive HSCs and activated HSCs have similar mRNA expression levels for GFAP, vascular cell adhesion molecule-1, fibulin 2, and vimentin. Telomerase-positive HSCs have higher mRNA expression for $\alpha 2$-macroglobulin than activated HSCs, whereas activated HSCs express higher mRNA levels of IL-6 than telomerase-positive HSCs. Thus, activated human HSCs and telomerase-positive HSCs show the neuroendocrine markers of HSCs but also some markers attributed to liver myofibroblasts. However, differences in the expression pattern of cytoskeletal filaments and cytokines between human and rat HSCs have been demonstrated (Nouchi et al, 1991; Schmitt-Graff et al, 1991).

Evidence that telomerase-positive HSCs maintain the phenotype of activated HSCs includes the fact that telomerase-positive human HSCs revert to a more quiescent phenotype and down-regulate their collagen type I expression after culturing them in a basement membrane-like matrix. This feature makes the cell line a valuable tool for investigating the transition from a quiescent to an activated phenotype. Similar to previous reports in rat and human HSCs (Murakami et al, 1995; Vogel et al, 2000), telomerase-positive HSCs uptake retinol and regain the characteristic fluorescence of vitamin A.

Taken together, these findings suggest that the cellular origin of telomerase-positive HSCs are activated HSCs and that introduction and expression of hTERT in human HSCs maintain their phenotypic and functional characteristics. In conclusion, our study demonstrates that activated human HSCs senesce and die in culture. Telomerase-positive human HSCs have an extended life span but show no sign of transformation, thereby making this new HSC cell line a useful and easy tool to study the cell biology of human HSCs.

\section{Materials and Methods}

\section{Isolation and Culture of Primary Human Hepatic Stellate Cells}

Surgical specimens of normal human liver were digested by a two-step collagenase perfusion of the liver as described previously (Sahi et al, 2000). Briefly, the encapsulated liver tissue was perfused with calcium-free buffer followed by perfusion with buffer containing $1.5 \mathrm{~mm}$ calcium and collagenase ( 0.3 to 0.4 $\mathrm{mg} / \mathrm{ml}$ ). Hepatocytes were pelleted by low-speed centrifugation at $50 \times g$ at room temperature, and the supernatant was digested with $0.035 \%$ pronase (Boehringer Mannheim, Indianapolis, Indiana) for 15 minutes at $37^{\circ} \mathrm{C}$. The cell suspension was layered on top of an arabinogalactan (Sigma, St. Louis, Missouri) two-layer discontinuous density gradient (densities of 1.035 and 1.058). The gradient was centrifuged, and HSCs were recovered from the interface of the supernatant and 1.035 gradient layer and were washed as described previously (Rippe et al, 1995). The purity after 4 days in culture was approximately $98 \%$ as estimated by autofluorescence. Cells were seeded on uncoated plastic tissue culture dishes and cultured in DMEM (GIBCO/BRL, Gaithersburg, Maryland) supplemented with $10 \% \mathrm{FCS}$ in $95 \%$ air/5\% $\mathrm{CO}_{2}$ humidified atmosphere at $37^{\circ} \mathrm{C}$. All human tissues were obtained through qualified medical staff, with donor consent and the approval of the University of North Carolina Ethics Committee.

\section{Retroviral Vectors and Infection of Human Hepatic Stellate Cells}

Human HSCs were trypsinized 8 days after isolation and seeded in 60-mm culture dishes at a density of $3.5 \times 10^{5}$ cells/dish. The cells were infected the next day with a VSV-G pseudotyped vector encoding hTERT (Geron, Menlo Park, California) driven by the CMV promoter or an amphotropic retrovirus containing the neomycin resistance gene alone as vector control (Johnson et al, 1998). Six days after infection, HSCs were selected in $400 \mu \mathrm{g} / \mathrm{ml} \mathrm{G} 418$ (GIBCO/BRL) for 21 days, after which the concentration of $\mathrm{G} 418$ was reduced to $200 \mu \mathrm{g} / \mathrm{ml}$. G418-resistant cells were grown to confluence and split between 1:2 and 1:5 using trypsin. Selection for individual cell clones was performed 21 days after infection. A single clone (no. 14) and a polyclonal HSC population were used for all experiments. HSCs from several different isolations, which were either left uninfected or were infected with the vector alone, served as controls. A second HSC cell line from a different human HSC isolation was established using the same transfection protocol. 
However, this cell line is not described in the present study.

\section{Telomerase Activity Assay}

Telomerase activity was measured using a polymerase chain reaction-based TRAP (Wright et al, 1995) using a kit from Roche (Indianapolis, Indiana) according to the manufacturer's protocol. Briefly, after trypsinization, $10^{5}$ cells were lysed in $200 \mu$ l of lysis reagent. Cells were centrifuged, and $175 \mu$ l of the supernatant was analyzed. After extension of the substrate by telomerase and amplification of the products by PCR, the products were run on a $12 \%$ polyacrylamide gel and visualized using Sybr Green (Molecular Probes, Eugene, Oregon) and a phosphorimager (Molecular Dynamics, Sunnyvale, California).

\section{Determination of Telomere Restriction Fragment Length}

The length of the telomere restriction fragment was determined by Southern blot analysis as described (Kojima et al, 1997). Briefly, genomic DNA was isolated using the DNeasy kit (Qiagen, Valencia, California) and $2 \mu \mathrm{g}$ of the isolated genomic DNA digested with Hinfl and Rsal, and fractionated in a $0.8 \%$ agarose gel. After transfer onto Magna Graph nylon transfer membrane (Osmonics, Minnetonka, Minnesota), the filter was hybridized with an oligonucleotide $(\text { CCCTAA })_{3}$, which was end-labeled with $\left[\gamma^{-32}\right.$ P]ATP. The filter was analyzed by autoradiography and by phosphorimager analysis (Molecular Dynamics). The maximal signal in each band was determined, and the length of the telomere restriction fragment calculated by comparison to that of a molecular size marker.

\section{Cell Proliferation Assays}

To assess the proliferation rate, HSCs were seeded and cultured in standard growth medium supplemented with 10\% FCS. HSCs were trypsinized and counted with a hemacytometer in duplicate. To determine whether the growth of telomerase-positive HSCs is serum dependent, $\left[{ }^{3} \mathrm{H}\right]$ thymidine incorporation assays were performed. HSCs were plated at a density of $1.25 \times 10^{4} /$ well in 24-well plates in Waymouth's MB752/1 Medium (GIBCO/BRL) containing 10\% FCS. The next day HSCs were starved in serum-free medium. After 24 hours, the cells were incubated in medium in the presence or absence of $10 \%$ FCS with $1 \mu \mathrm{Ci} / \mathrm{ml}\left[{ }^{3} \mathrm{H}\right]$ thymidine. After 24 hours of incubation, the cells were washed three times with cold PBS, and then $10 \%$ trichloric acetic acid was added. After incubation on ice for 1 hour, the solution was removed and the cells were washed once with $10 \%$ trichloric acetic acid. The samples were solubilized in $0.2 \mathrm{~N}$ $\mathrm{NaOH}$, and radioactivity was measured using a scintillation counter. Experiments were performed in triplicate.

\section{Soft Agar Assay}

A soft agar assay was performed as described previously (Cox and Der, 1994). Briefly, 0.6\% agar (in growth medium) was poured in $60-\mathrm{mm}$ dishes and allowed to solidify. Cells were trypsinized and counted (using trypan blue staining), and then $10^{5}$ cells were suspended in $0.4 \%$ agar (in growth medium) to form the top layer in a 60-mm dish. After solidification of the top layer, the plates were incubated in a humidified $10 \% \mathrm{CO}_{2}$ incubator at $37^{\circ} \mathrm{C}$. Cells were fed weekly by the addition of regular growth medium. Rastransformed (pZIP-H-ras(61L)) NIH 3T3 cells were used as a positive control. NIH 3T3 cells, transfected with the empty vector pZIP-NeoSV(x)1, were used as a negative control. Cells were kept in soft agar for 6 weeks.

\section{Preparation of RNA and cDNA Microarrays}

Total RNA was isolated from subconfluent cultureactivated human HSCs (passage 3) and from telomerase-positive HSCs (passage 55), grown in regular growth medium, using Tri Reagent (Molecular Research Center Inc., Cincinnati, Ohio) according to the manufacturer's protocol. Poly $(A)$ mRNA was isolated from total RNA using oligo(dT) (Oligotex; Qiagen) according to the manufacturer's protocol.

All microarray procedures were performed by Incyte Genomics (St. Louis, Missouri). Equal quantities of mRNA from each cell type were used to prepare probes, hybridized to gene chips, and analyzed for the quantity of mRNA encoded by over 9000 human genes (Human UniGene 1). The preparation of Cy3 and Cy5 probes from mRNA samples and the hybridization studies were conducted by Incyte Genomics.

\section{RNA Isolation and RNase Protection Assay}

RNA was isolated from subconfluent HSCs using an RNA extraction kit (Qiagen) according to the manufacturer's protocol. Riboprobes were derived from the plasmid pTRI-GAPDH-human (Ambion, Austin, Texas), and from the 142-nt Xbal-Kpnl fragment of human $\alpha 1$ (I) collagen (ATCC 61322), cloned into Kpnl-Xbal sites of vector Bluescript SK, and linearized with Sacl (Stefanovic et al, 2000). RNase protection assays were performed as described previously (Lang et al, 2000). Total RNA was hybridized with $10^{5} \mathrm{cpm}$ of each riboprobe. The RNase protected riboprobes were separated in $6 \%$ sequencing gels, the gels were dried, and the bands were visualized by autoradiography and quantitated by phosphorimager analysis (Molecular Dynamics).

\section{Western Blot Analysis}

Western blot analysis was performed as described previously (Schnabl et al, 2001). The primary antibody of mouse anti- $\alpha$ SMA (DAKO, Carpinteria, California) was diluted 1:1000.

\section{Reverse Transcriptase-Polymerase Chain Reaction Assays}

RT-PCR was performed exactly as described previously (Schnabl et al, 2001) using specific primers for 
hTERT (Nakamura et al, 1997). Primer sequences for ubiquitin, used as a control, were 5'-GGAAGACCATCACCCTCGAGG-3' and 5'-CCAGCACCACATTCATC-3'. Expected lengths of the amplified products for hTERT and ubiquitin were 145 and 357 basepairs, respectively. PCR reactions contained $1 \mu \mathrm{l}$ of CDNA for hTERT or $0.25 \mu \mathrm{l}$ of cDNA for ubiquitin, $1 \times$ Opti-Prime buffer no. 5 (Stratagene, La Jolla, California) for hTERT or $1 \times$ PCR-buffer II (Perkin Elmer, Branchburg, New Jersey) for ubiquitin, $1 \mu \mathrm{M}$ of each primer, $0.25 \mathrm{~mm}$ of each dNTP (Pharmacia, Piscataway, New Jersey), and 2.5 U Taq-polymerase (Perkin Elmer) in a total volume of $50 \mu \mathrm{l}$. PCR reactions were cycled as follows: initial denaturation at $99^{\circ} \mathrm{C}$ for 4 minutes; $94^{\circ} \mathrm{C}$ for 45 seconds, $60^{\circ} \mathrm{C}$ for 45 seconds, $72^{\circ} \mathrm{C}$ for 90 seconds for 30 cycles. A final extension at $72^{\circ} \mathrm{C}$ for 10 minutes was performed. The cycle number for each amplicon was determined to be in the linear range of amplification. Negative controls without CDNA were performed with each PCR reaction. PCR products were analyzed by $2 \%$ agarose gel electrophoresis with ethidium bromide staining.

\section{Matrigel Experiments}

Tissue culture dishes were coated with liquid matrigel (diluted 1:3 in PBS, 2 ml/60-mm dish; Becton Dickinson, Bedford, Massachusetts) and allowed to gel at $37^{\circ} \mathrm{C}$ for 30 minutes. Telomerase-positive HSCs were plated at 4 to $6 \times 10^{5}$ per $60-\mathrm{mm}$ dish on top of the matrigel. Cells were allowed to attach for 6 hours, and then the medium was aspirated and the cells were covered with $2 \mathrm{ml}$ of matrigel. HSCs were maintained in HDM containing $5 \mu \mathrm{g} / \mathrm{ml}$ insulin, $5 \mu \mathrm{g} / \mathrm{ml}$ transferrin, $0.1 \mu \mathrm{m}$ selenium, $50 \mathrm{ng} / \mathrm{ml}$ epidermal growth factor, 10 $\mu \mathrm{g} / \mathrm{ml}$ high-density lipoproteins, $7.6 \mathrm{~nm} / \mathrm{ml}$ free fatty acids, $10^{-2}$ nм hydrocortisone, $10^{-3} \mathrm{~nm} \mathrm{~T}_{3}$ (3,5,3'Triiodothyronine), $10 \mathrm{ng} / \mathrm{ml}$ prolactin, $10^{-4} \mathrm{~nm}$ zinc, 0.1 nм copper, $10 \mathrm{ng} / \mathrm{ml}$ human growth hormone (somatotropin), and 2\% FCS in RPMI basal medium (GIBCO/ $\mathrm{BRL}$ ). Fresh culture media was added every other day. After 15 days of culture in matrigel, HSCs were released from the matrix with Matri Sperse (Becton Dickinson) according to the manufacturer's protocol, and RNA was prepared as described above.

\section{Retinol Administration}

Telomerase-positive HSCs from clone 14 were incubated with retinol as described (Murakami et al, 1995). All-trans-retinol (Sigma) was dissolved in $200 \mu \mathrm{l}$ of ethanol, diluted to $3 \mathrm{ml}$ with PBS, and filter sterilized through a $0.22-\mu \mathrm{m}$ filter. The concentration of retinol was determined by spectrophotometry at $325 \mathrm{~nm}$. The solution was diluted with standard growth medium to a final retinol concentration of $1.5 \mu \mathrm{M}$, and HSCs were maintained in the dark for 14 days. As a control HSCs were treated in the same manner with an equivalent amount of vehicle (ethanol).

\section{Acknowledgements}

We thank Dr. Patricia A. Solski, Dr. Geraldine Hamilton, Mr. Robert Schoonhoven, and Dr. Scott $\mathrm{H}$. Randell for experimental assistance.

\section{References}

Allsopp RC, Vaziri H, Patterson C, Goldstein S, Younglai EV, Futcher AB, Greider CW, and Harley CB (1992). Telomere length predicts replicative capacity of human fibroblasts. Proc Natl Acad Sci USA 89:10114-10118.

Blomhoff R and Wake K (1991). Perisinusoidal stellate cells of the liver: Important roles in retinol metabolism and fibrosis. FASEB J 5:271-277.

Bodnar AG, Ouellette M, Frolkis M, Holt SE, Chiu CP, Morin GB, Harley CB, Shay JW, Lichtsteiner S, and Wright WE (1998). Extension of life-span by introduction of telomerase into normal human cells. Science 279:349-352.

Counter CM, Avilion AA, LeFeuvre CE, Stewart NG, Greider CW, Harley CB, and Bacchetti S (1992). Telomere shortening associated with chromosome instability is arrested in immortal cells which express telomerase activity. EMBO J 11:19211929.

Counter CM, Hahn WC, Wei W, Caddle SD, Beijersbergen RL, Lansdorp PM, Sedivy JM, and Weinberg RA (1998). Dissociation among in vitro telomerase activity, telomere maintenance, and cellular immortalization. Proc Natl Acad Sci USA 95:14723-14728.

Cox AD and Der CJ (1994). Biological assays for cellular transformation. Methods Enzymol 238:277-294.

de Lange T, Shiue L, Myers RM, Cox DR, Naylor SL, Killery AM, and Varmus HE (1990). Structure and variability of human chromosome ends. Mol Cell Biol 10:518-527.

de Leeuw AM, McCarthy SP, Geerts A, and Knook DL (1984). Purified rat liver fat-storing cells in culture divide and contain collagen. Hepatology 4:392-403.

Friedman SL (2000). Molecular regulation of hepatic fibrosis, an integrated cellular response to tissue injury. $\mathrm{J}$ Biol Chem 275:2247-2250.

Friedman SL, Rockey DC, McGuire RF, Maher JJ, Boyles JK, and Yamasaki G (1992). Isolated hepatic lipocytes and Kupffer cells from normal human liver: Morphological and functional characteristics in primary culture. Hepatology 15 : 234-243.

Friedman SL, Roll FJ, Boyles J, Arenson DM, and Bissell DM (1989). Maintenance of differentiated phenotype of cultured rat hepatic lipocytes by basement membrane matrix. J Biol Chem 264:10756-10762.

Funk WD, Wang CK, Shelton DN, Harley CB, Pagon GD, and Hoeffler WK (2000). Telomerase expression restores dermal integrity to in vitro-aged fibroblasts in a reconstituted skin model. Exp Cell Res 258:270-278.

Geerts A, Lazou JM, De Bleser P, and Wisse E (1991). Tissue distribution, quantitation and proliferation kinetics of fatstoring cells in carbon tetrachloride-injured rat liver. Hepatology 13:1193-1202.

Greider CW and Blackburn EH (1989). A telomeric sequence in the RNA of tetrahymena telomerase required for telomere repeat synthesis. Nature 337:331-337. 
Hahn WC, Counter CM, Lundberg AS, Beijersbergen RL, Brooks MW, and Weinberg RA (1999). Creation of human tumour cells with defined genetic elements. Nature 400:464468.

Harley CB, Futcher AB, and Greider CW (1990). Telomeres shorten during ageing of human fibroblasts. Nature 345:458460.

Johnson LG, Mewshaw JP, Ni H, Friedmann T, Boucher RC, and Olsen JC (1998). Effect of host modification and age on airway epithelial gene transfer mediated by a murine leukemia virus-derived vector. J Virol 72:8861-8872.

Karlseder J, Broccoli D, Dai Y, Hardy S, and de Lange T (1999). p53- and ATM-dependent apoptosis induced by telomeres lacking TRF2. Science 283:1321-1325.

Kim NW, Piatyszek MA, Prowse KR, Harley CB, West MD, Ho PL, Coviello GM, Wright WE, Weinrich SL, and Shay JW (1994). Specific association of human telomerase activity with immortal cells and cancer. Science 266:2011-2015.

Kiyono T, Foster SA, Koop JI, McDougall JK, Galloway DA, and Klingelhutz AJ (1998). Both Rb/p16INK4a inactivation and telomerase activity are required to immortalize human epithelial cells. Nature 396:84-88.

Knittel T, Kobold D, Saile B, Grundmann A, Neubauer K, Piscaglia F, and Ramadori G (1999). Rat liver myofibroblasts and hepatic stellate cells: Different cell populations of the fibroblast lineage with fibrogenic potential. Gastroenterology 117:1205-1221.

Kojima H, Yokosuka O, Imazeki F, Saisho H, and Omata M (1997). Telomerase activity and telomere length in hepatocellular carcinoma and chronic liver disease. Gastroenterology 112:493-500.

Lang A, Schoonhoven R, Tuvia S, Brenner DA, and Rippe RA (2000). Nuclear factor kappaB in proliferation, activation, and apoptosis in rat hepatic stellate cells. J Hepatol 33:49-58.

Lee HW, Blasco MA, Gottlieb GJ, Horner JW, 2nd, Greider CW, and DePinho RA (1998). Essential role of mouse telomerase in highly proliferative organs. Nature 392:569-574.

Liu K, Schoonmaker MM, Levine BL, June CH, Hodes RJ, and Weng NP (1999). Constitutive and regulated expression of telomerase reverse transcriptase (hTERT) in human lymphocytes. Proc Natl Acad Sci USA 96:5147-5152.

Maher JJ, Bissell DM, Friedman SL, and Roll FJ (1988). Collagen measured in primary cultures of normal rat hepatocytes derives from lipocytes within the monolayer. $\mathrm{J}$ Clin Invest 82:450-459.

Maher JJ and McGuire RF (1990). Extracellular matrix gene expression increases preferentially in rat lipocytes and sinusoidal endothelial cells during hepatic fibrosis in vivo. J Clin Invest 86:1641-1648.

Mak KM, Leo MA, and Lieber CS (1984). Alcoholic liver injury in baboons: Transformation of lipocytes to transitional cells. Gastroenterology 87:188-200.

Meyerson M, Counter CM, Eaton EN, Ellisen LW, Steiner P, Caddle SD, Ziaugra L, Beijersbergen RL, Davidoff MJ, Liu Q, Bacchetti S, Haber DA, and Weinberg RA (1997). hEST2, the putative human telomerase catalytic subunit gene, is upregulated in tumor cells and during immortalization. Cell 90:785-795.

Morales CP, Holt SE, Ouellette M, Kaur KJ, Yan Y, Wilson KS, White MA, Wright WE, and Shay JW (1999). Absence of cancer-associated changes in human fibroblasts immortalized with telomerase. Nat Genet 21:115-118.

Morin GB (1989). The human telomere terminal transferase enzyme is a ribonucleoprotein that synthesizes TTAGGG repeats. Cell 59:521-529.

Moyzis RK, Buckingham JM, Cram LS, Dani M, Deaven LL, Jones MD, Meyne J, Ratliff RL, and Wu JR (1988). A highly conserved repetitive DNA sequence, (TTAGGG)n, present at the telomeres of human chromosomes. Proc Natl Acad Sci USA 85:6622-6626.

Murakami K, Abe T, Miyazawa M, Yamaguchi M, Masuda T, Matsuura T, Nagamori S, Takeuchi K, Abe K, and Kyogoku M (1995). Establishment of a new human cell line, LI90, exhibiting characteristics of hepatic Ito (fat-storing) cells. Lab Invest 72:731-739.

Nakamura TM, Morin GB, Chapman KB, Weinrich SL, Andrews WH, Lingner J, Harley CB, and Cech TR (1997). Telomerase catalytic subunit homologs from fission yeast and human. Science 277:955-959.

Neubauer K, Knittel T, Aurisch S, Fellmer P, and Ramadori G (1996). Glial fibrillary acidic protein: A cell type specific marker for Ito cells in vivo and in vitro. J Hepatol 24:719-730.

Niida H, Matsumoto T, Satoh H, Shiwa M, Tokutake $Y$, Furuichi Y, and Shinkai Y (1998). Severe growth defect in mouse cells lacking the telomerase RNA component. Nat Genet 19:203-206.

Nouchi T, Tanaka Y, Tsukada T, Sato C, and Marumo F (1991). Appearance of alpha-smooth-muscle-actin-positive cells in hepatic fibrosis. Liver 11:100-105.

Ramadori G, Veit T, Schwogler S, Dienes HP, Knittel T, Rieder H, and Meyer zum Buschenfelde KH (1990). Expression of the gene of the alpha-smooth muscle-actin isoform in rat liver and in rat fat-storing (ITO) cells. Virchows Arch B Cell Pathol Incl Mol Pathol 59:349-357.

Rippe RA, Almounajed G, and Brenner DA (1995). Sp1 binding activity increases in activated Ito cells. Hepatology 22:241-251.

Sahi J, Hamilton G, Sinz M, Barros S, Huang SM, Lesko LJ, and LeCluyse EL (2000). Effect of troglitazone on cytochrome P450 enzymes in primary cultures of human and rat hepatocytes. Xenobiotica 30:273-284.

Schmitt-Graff A, Kruger S, Bochard F, Gabbiani G, and Denk $H$ (1991). Modulation of alpha smooth muscle actin and desmin expression in perisinusoidal cells of normal and diseased human livers. Am J Pathol 138:1233-1242.

Schnabl B, Kweon YO, Frederick JP, Wang XF, Rippe RA, and Brenner DA (2001). The role of Smad3 in mediating mouse hepatic stellate cell activation. Hepatology 34:89100.

Stefanovic B, Lindquist J, and Brenner DA (2000). The 5' stem-loop regulates expression of collagen alpha1(I) mRNA in mouse fibroblasts cultured in a three-dimensional matrix. Nucleic Acids Res 28:641-647.

Takahara T, Kojima T, Miyabayashi C, Inoue K, Sasaki H, Muragaki $Y$, and Ooshima A (1988). Collagen production in fat-storing cells after carbon tetrachloride intoxication in the rat: Immunoelectron microscopic observation of type I, type III collagens, and prolyl hydroxylase. Lab Invest 59:509-521.

Vaziri H and Benchimol S (1998). Reconstitution of telomerase activity in normal human cells leads to elongation of 
telomeres and extended replicative life span. Curr Biol 8:279-282.

Vogel S, Piantedosi R, Frank J, Lalazar A, Rockey DC, Friedman SL, and Blaner WS (2000). An immortalized rat liver stellate cell line (HSC-T6): A new cell model for the study of retinoid metabolism in vitro. J Lipid Res 41:882-893.

Weill FX, Blazejewski S, Blanc JF, Huet S, Gauthier JM, Neaud V, Olaso E, Dubuisson L, Azais-Braesco V, VidalVanaclocha F, Balabaud C, Bioulac-Sage P, and Rosenbaum $\mathrm{J}$ (1997). Characterization of a new human liver myofibroblast cell line: Transcriptional regulation of plasminogen activator inhibitor type I by transforming growth factor beta 1. Lab Invest 77:63-70.
Wright WE, Shay JW, and Piatyszek MA (1995). Modifications of a telomeric repeat amplification protocol (TRAP) result in increased reliability, linearity and sensitivity. Nucleic Acids Res 23:3794-3795.

Yang J, Chang E, Cherry AM, Bangs CD, Oei Y, Bodnar A, Bronstein A, Chiu CP, and Herron GS (1999). Human endothelial cell life extension by telomerase expression. J Biol Chem 274:26141-26148. 